\title{
Isolated glycerol kinase deficiency
}

INSERM

\section{Source}

INSERM. (1999). Orphanet: an online rare disease and orphan drug data base. Isolated glycerol kinase deficiency. ORPHA:408

Isolated glycerol kinase deficiency (GKD) is a very rare X-linked disorder of glycerol metabolism characterized biochemically by elevated plasma and urine glycerol levels, and clinically by variable neurometabolic manifestations, depending on the age of onset, and varying from a life-threatening childhood metabolic crisis to an asymptomatic adult form (infantile GKD, juvenile GKD, and adult GKD (see these terms)). 